\title{
The Role of Savings Group on the Nutritional and Economic Wellbeing of Rural Households: The Case of World Vision's Savings for Transformation (S4T) in Zambia
}

\author{
Richard Bwalya (Corresponding author) \\ Research Fellow, Institute of Economic and Social Research \\ University of Zambia, Box 30900, Lusaka, Zambia
}

Tel: 260-971-191-231Ｅ-mail: richkabemba@yahoo.com

Mabvuto Zulu

World Vision Zambia, Box 31083, Lusaka, Zambia

Tel: 260-971-252-343Ｅ-mail: mabvuto_zulu@wvi.org

Received: February 5, 2021 Accepted: March 18, $2021 \quad$ Published: March 24, 2021

doi:10.5296/ber.v11i2.18451ＵRL: https://doi.org/10.5296/ber.v11i2.18451

\begin{abstract}
Smallholders and the poor populations, especially in rural areas, tend to have little or no access to formal credit, which limits their capacity to invest in the technologies and inputs they need to increase their yields and incomes and reduce hunger and poverty. This mainly arises because financial institutions interested in serving this market face a myriad of risks and challenges associated with agricultural production and lending, including seasonality and the associated irregular cash flows, high transaction costs, and systemic risks, such as floods, droughts, and plant diseases. As a solution to the challenge of financial exclusion among the rural poor, several international development organizations have been using Village Savings and Lending Associations (VSLAs) as an alternative option to increasing financial inclusion among the rural communities in most developing countries. Using both quantitative and qualitative methods, this study aimed to assess whether membership to these VSLAs results in significant improvements in household economic status as well as household food security. The results show that compared to non-members, members of these savings groups are more likely to have increased access to alternative and more sustainable financial tools.
\end{abstract}


Membership to these savings groups is also associated with improved nutrition, education, living standards while the likelihood of being poor is also reduced.

Keywords: World Vision, Savings groups, Poverty, Food Security, Nutrition, Finance

\section{Introduction}

Since the early 1990s when CARE Niger took up the challenge of providing financial services to the poor in remote areas through accumulating savings and credit association (ACSA) model, the model has gained so much popularity and variations of the model have been widely adopted by various other large international non-government organizations. Currently, these development agencies are estimated to be reaching out to almost 2.3 million people mostly in Africa (Allen \& Panetta, 2010). Close to 800 million people around the world (or 78 percent of the world's poor people) live in rural areas and rely on farming, livestock, aquaculture, and other agricultural work to put food on their plates and make a living (IFC, 2011). These smallholders also play a key role in increasing food supply, more so than large farms in poor countries, and increasingly supply large conglomerates and corporations with inputs for their products (Carroll et al., 2012). However, despite their socioeconomic importance, smallholders tend to have little or no access to formal credit, which limits their capacity to invest in the technologies and inputs they need to increase their yields and incomes and reduce hunger and poverty (IFC, 2013).

Evidence from several FinScope studies in African suggests that less than half of the population has access to any form of financial services, whether formal or informal. Furthermore, the majority of those with access to banks and MFIs are mostly found in urban and peri-urban areas while the rural poor tend to lack access to financial services. The challenges to increasing access to financial services, especially to low-income communities in peri-urban and rural areas, are numerous and well documented. Financial institutions interested in serving these markets face a myriad of risks and challenges associated with agricultural production and lending, including seasonality and the associated irregular cash flows, high transaction costs, and systemic risks, such as floods and droughts. In response to the challenges associated with accessing formal financial services, especially among the rural poor, the Village Savings and Loan Associations (VSLA) were conceived as an alternative to the formal financial sector. These are community-based, user-owned, and self-managed savings and lending vehicles built on the concepts of transparency and flexibility.

The VSLAs are part of microfinance organizations under the generic term "Community Managed Microfinance" (CMM), which facilitates saving as well as borrowing for rural and poor populations (Rasmussen, 2011; Ritchie, 2010; Rooyenet et al., 2012). Since their establishment in the early 1990s, VSLAs have shown promise to attain outreach and impact to rural people better than formal, centralized microfinance institutions (Rooyenet et al., 2012). By pooling their resources, group members, who are normally vulnerable small-scale farming households that are not able to access financial services as they are regarded as being low profile and high risk, can diversify and increase their incomes by borrowing group funds at agreed interest. The savings serve as a group social insurance fund, and they enable members to invest in small businesses, plan or cope with household emergencies. 


\section{\لMacrothink}

Business and Economic Research ISSN 2162-4860 2021, Vol. 11, No. 2

The VSLA model has been implemented widely by several development organizations especially in poor Asian and African countries, with anecdotal evidence suggesting that it indeed provides a wide range of benefits for the members and their families. However, while there is a growing body of evidence evaluating the impact of the VSLAs, their focus has been primarily on how these VSLA's influence poor people's access to credit and savings (Ashraf et al., 2006; Rasmussen, 2011; Ritchie, 2010; Rooyenet et al., 2012). Therefore, using evidence from Zambia, this paper aims to contribute to this growing body of literature on VSLAs by assessing whether membership in these groups does contribute to significant reductions in poverty and household food security.

\subsection{Study Setting}

Just like in many other poor countries in Africa, a large proportion of the rural poor in Zambia lack access to formal financial services. Even though there has been a significant increase in financial inclusion from 37.3 percent in 2009 to 59.3 percent in 2015 driven by growth in both the formal (from 23.1 percent to 38.2 percent) and informal sectors $(22.2$ percent to 37.9 percent) between the two periods respectively, majority of this growth is accounted for by growth in urban areas as opposed to rural areas (FinScope, 2015). The low levels of financial inclusion in Zambia are a result of the high cost of providing financial services, particularly in rural areas and to poorer populations. Serving poorer communities generally results in lower revenue for financial service providers given poor households have limited investment opportunities and small transaction amounts (Ledgerwood \& White, 2006). This often means banks and MFIs lack the incentives, information, and sometimes the ability to mitigate perceived risks of operating beyond urban markets or with poor clients.

The Zambian government has not been oblivious to the challenges faced by Zambians when it comes to accessing financial services. For instance, Zambia launched its first-ever National Financial Inclusion Strategy in November 2017. The Strategy is supposed to guide Zambia in its plan to achieve the universal access and use of a broad range of affordable financial products and services and guide Zambia to meet several targets among which include an increase in overall financial inclusion (formal as well as informal) from the current 59 percent to 80 percent by 2022 (MoF, 2017). Similarly, in line with the aspirations of the Zambian Government as well as international commitments such as Sustainable Development Goal 1, World Vision Zambia (WVZ) is committed to ending poverty in all its forms everywhere. To this end, WVZ's work aims to address the underlying drivers of child poverty, food and nutrition insecurity, unjust market systems, lack of access to financial services, and vulnerability to climate change and disaster risk (WVI, 2017).

One of the strategies that WVZ uses to achieve the above is the Savings for Transformation (S4T) model. The S4T model, which is just one of the many variants of the VSLA model, tries to connect the most vulnerable and marginalized individuals (such as the women and persons with disabilities) and households in the community, to cheap and accessible sources of financing. By introducing S4T groups into communities, World Vision facilitates a sustainable platform for families to access savings and small loans. The model builds resilience by enabling community members to develop skills and access to funds to cope with household 
emergencies, learn long-term coping strategies, focus on the health, nutrition, and education of their children, and invest in their livelihoods. The goal of WVZ's S4T program is to contribute to improved and resilient livelihood for 45,378 households (232,060 people) by 2021 . Among the program outcomes include improving access to financial services for entrepreneurs by addressing practical and systematic barriers to financial inclusion for poor households and rural enterprises and provide a buffer against shocks through savings and micro-insurance services (World Vision Zambia Limited, 2016).

\subsection{S4T Pathway of Change}

To assess the impact of the savings groups, we adopt a theory of change used by Karlan et al. (2012). Using this theory, we hypothesize that VSLAs can lead to changes in the tools that respondents use to manage expenditures and investments. These short-term changes in behavior, and the prolonged usage of a wider set of financial tools, may in the long run lead to the creation of wealth and ultimately, changes in the well-being of households. This theory is also in line with WVZ's integrated and tailored pathway out of extreme poverty by focusing on equipping families with the knowledge, skills, and resources. Its goal, under the S4T program, is to increase the economic capacity of parents and caregivers to provide well for their children. This goal is supposed to be achieved through improved household food and nutrition security, increased household resilience to shocks and stresses, establishing income diversity and security as well as increased hope for the future (Figure 1).
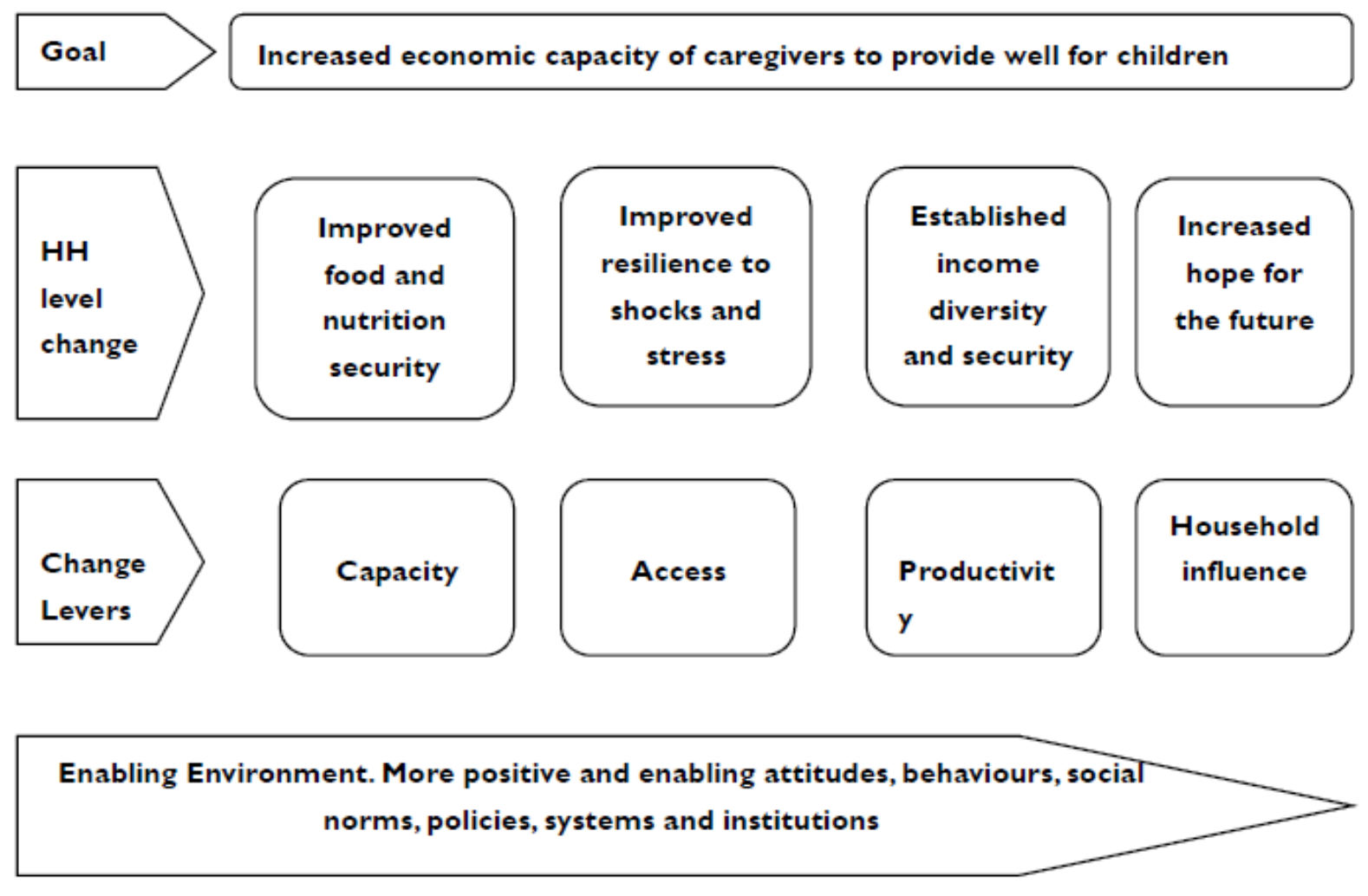

Figure 1. S4T Pathway of Change

Source: World Vision International (2016), with minor adaptations 


\subsection{Data Collection}

This study used a mixed-methods design. It was structured as a case study using mixed methods, drawing on the strengths of both in-depth qualitative interviews and quantitative surveys to uncover how key household-level shocks have evolved given the introduction of the savings groups. Besides, the interviews and surveys documented the benefits that members obtain from these groups and how these impact the sustainability of these groups. The survey was conducted in Northern and Eastern provinces and covered three out of the 33 districts in which WVZ operates namely Katete, Lundazi, and Kasama. The selection of the study sites was mainly guided by the experience the sites had with implementing Village Saving and Lending Associations (VSLAs). Consequently, Katete and Mwamba were selected on the basis that the districts had just started implementing the S4T program, while Lundazi was purposely selected based on it being one of the areas in which the VSLAs have been in existence for a much longer period.

The selection of the study sites and the participant recruitment was done using a multi-stage sampling process. This entailed the use of a 2-stage cluster sampling design with probability proportional to size (PPS) to obtain the sampled individuals. The first stage involved selecting the S4T groups. These were randomly selected from the lists of S4T groups operating in the districts using systematic sampling using a random starting point. The second stage involved the selection of individuals from the groups using systematic sampling and a random starting point. The saving group registers were used as sampling lists. Considering that the desired sample size was 300 respondents per district, of which 150 were members from S4T groups and the other 150 were non-members (control group) but beneficiaries of World Vision programs, we ended up selecting 15 groups from each district and ten members from each of the selected groups. For each one of the S4T groups selected, a control group with 10 members was selected using the same criteria, with the program beneficiary lists being used as sampling frames. Qualitative data were mainly obtained from the Community Agents (CAs) who are responsible for coordinating the selected groups. Additionally, two randomly selected members from the groups were also included in the qualitative sample.

\subsection{Data Analysis}

The quantitative data analysis mainly focuses on making comparisons between those households participating in the savings groups and those that are not participating on indicators such as access to credit and savings, access to education for the children, access to food, access to assets as well as levels of poverty as computed using Poverty Probability Index (PPI). This was done using tests such as t-tests to compare differences between means as well as chi-square tests to test for associations between membership to VSLAs and other key variables of interest. The qualitative data were analyzed using the Constant Comparison Analysis. This entailed breaking down the interviews by section and question into small response chunks. Each response chunk was allotted a particular code, and all future responses that expressed a similar idea were allotted the same code. Hence, the codes allowed the researchers to judge the frequency of an expressed idea. The prevalent codes were then grouped to produce a Code Frequency Report, which was then used to identify trends and themes. 


\section{Results}

\subsection{Demographic Characteristics}

Demographic characteristics such as age and sex have been shown to influence financial inclusion (FinScope, 2015). As such, comparisons are made using variables such as family size, age of the person, education level, and sex between the savings group members and non-savings group members to assess whether these groups differ significantly. Table 1 presents the comparisons in the mean household size and the mean age of the respondents between savings group members and non-savings group members. The mean number of household members for savings group members was larger than that for non-saving group members. This difference is statistically significant $(t=5.281 ; p<0.05)$. Similarly, the mean age for savings group members was larger than that for non-savings group members. This difference is also statistically significant $(t=5.117 ; p<0.05)$

Table 1. Comparisons of household size and age of respondents between saving group members and non-saving group members

\begin{tabular}{|l|l|l|l|l|l|}
\hline Variable & Category & $\mathbf{n}$ & Mean & t-value & p-value \\
\hline \multirow{2}{*}{ Household size } & Members & 540 & 6.41 & 5.281 & 0.000 \\
\cline { 2 - 6 } & Non-members & 484 & 5.58 & & \\
\hline \multirow{2}{*}{ Age in years } & Members & 540 & 40.8 & 5.117 & 0.000 \\
\cline { 2 - 6 } & Non-members & 480 & 36.8 & & \\
\hline
\end{tabular}

Table 2 presents the comparisons in the proportion of female respondents as well as the proportion of respondents who had acquired secondary school education or higher between savings group members and non-savings group members. The proportion of female respondents was significantly higher among savings group members compared to non-savings group members $(\chi 2=99.780, d . f .=1, p<0.05)$. With regards to the proportion of respondents whose highest level of education was secondary school and above, we find no significant differences between the two groups $\left(\chi^{2}=0.209\right.$, d.f. $\left.=1, p=0.648\right)$.

Table 2. Comparison between the proportion of female respondents and proportion of respondents with secondary education of higher between the groups

\begin{tabular}{|l|l|l|l|l|l|}
\hline Variable & Category & $\mathbf{n}$ & Percentage & Chi-square & p-value \\
\hline Female respondents & Members & 540 & 63.5 & 99.780 & 0.000 \\
\cline { 2 - 5 } & Non-members & 484 & 56.4 & & \\
\hline \multirow{2}{*}{ Secondary school or higher } & Members & 540 & 30.9 & 0.209 & 0.648 \\
\cline { 2 - 4 } & Non-members & 480 & 32.2 & & \\
\hline
\end{tabular}

\subsection{Impact of Savings Group Membership on Household Welfare}

In this section, we assessed whether membership to savings groups is associated with improved nutrition at the household level; increased access to household assets; increased access to education as well as a reduced likelihood of households living below the national poverty line. Our results are organized around Karlan et al. (2012) and World Vision's theory 
of change and test for impacts of VSLA membership on i) financial management; ii) income-generating activities; iii) reaction to shocks; iv) food security; v) access to education for the children in the households and v) asset accumulation.

\subsubsection{Financial Management}

For purposes of this study, financial management was measured using several parameters namely being able to save money, whether a household borrowed money as well as the sources from which the money was borrowed for those that borrowed money. As expected, the proportion of saving group members that indicated that they had saved money in the previous twelve months was much higher (91.1 percent) than that for non-members $(26.2$ percent). This difference is statistically significant implying a significant association $(\chi 2=$ 454.025 , d.f. $=1, p<0.05)$ between membership to savings groups and having saved some money in the previous twelve months. Furthermore, an inspection of the phi coefficient suggests a very strong and significant relationship $(\varphi=0.663, n=1,034, p<0.01)$ between membership to savings groups and having saved some money in the previous twelve months. These findings are collaborated by findings from other studies that show that savings groups increase financial inclusion for the rural poor. For instance, Karlan et al. (2017) show that the promotion of savings groups in Ghana, Malawi, and Uganda resulted in an improvement in financial inclusion for women for whom savings increased by 34 percent relative to the comparison group, while access to credit increased by 11 percent compared to the comparison group. Similarly, in Ghana, a study by CARE International shows significant differences between the proportion of cocoa farmers that were members of savings groups that reported saving and accessing loans compared to non-members (Hinson et al., 2017).

Figure 2 also presents a comparison of the proportions of respondents that indicated that they had borrowed money in the previous twelve months. The proportion of saving group members that indicated that they had borrowed money in the previous twelve months was much higher (70.5 percent) than that for non-members (27.1 percent). This difference is statistically significant implying a significant association $(\chi 2=194.679$, d.f. $=1, p<0.05)$ between membership to savings groups and access to credit or indeed having borrowed money in the previous twelve months. Inspection of the phi coefficient suggests a very strong and significant relationship ( $\varphi=0.434, n=1,034, p<0.01)$ between membership to savings groups and having saved some money in the previous twelve months.

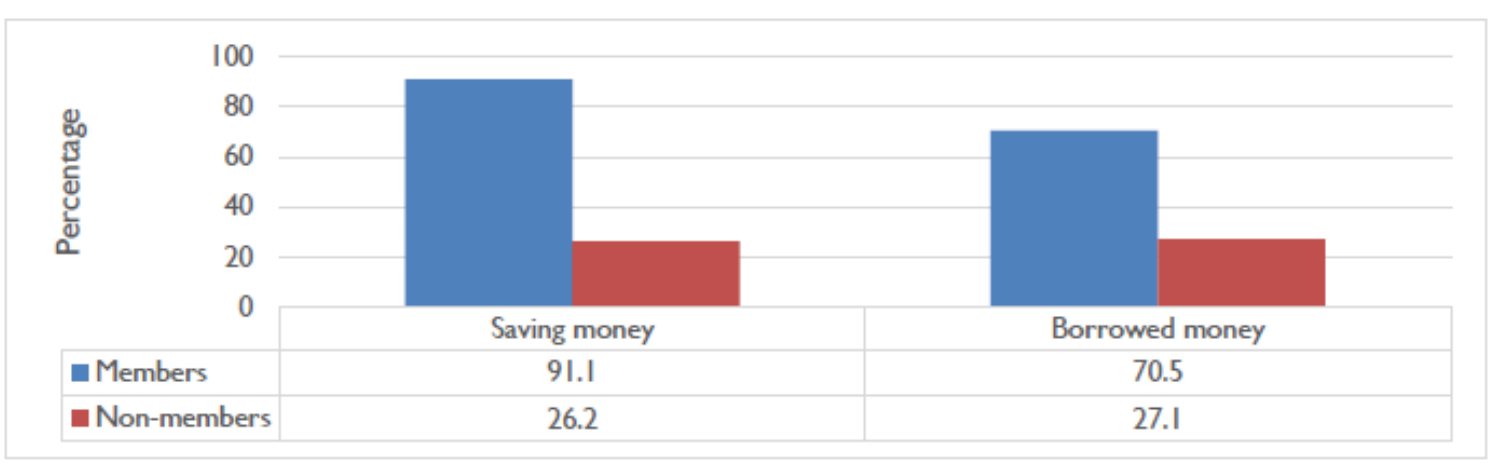

Figure 2. Proportions of households that borrowed and saved money in the past 12 months 
We also compare the sources of credit for those who reported having borrowed money. Again as expected, the results (Figure 3) show that majority of the savings group members reported having borrowed from the groups. On the other hand, for those who are not in the savings groups, the main source of credit remains family and friends.

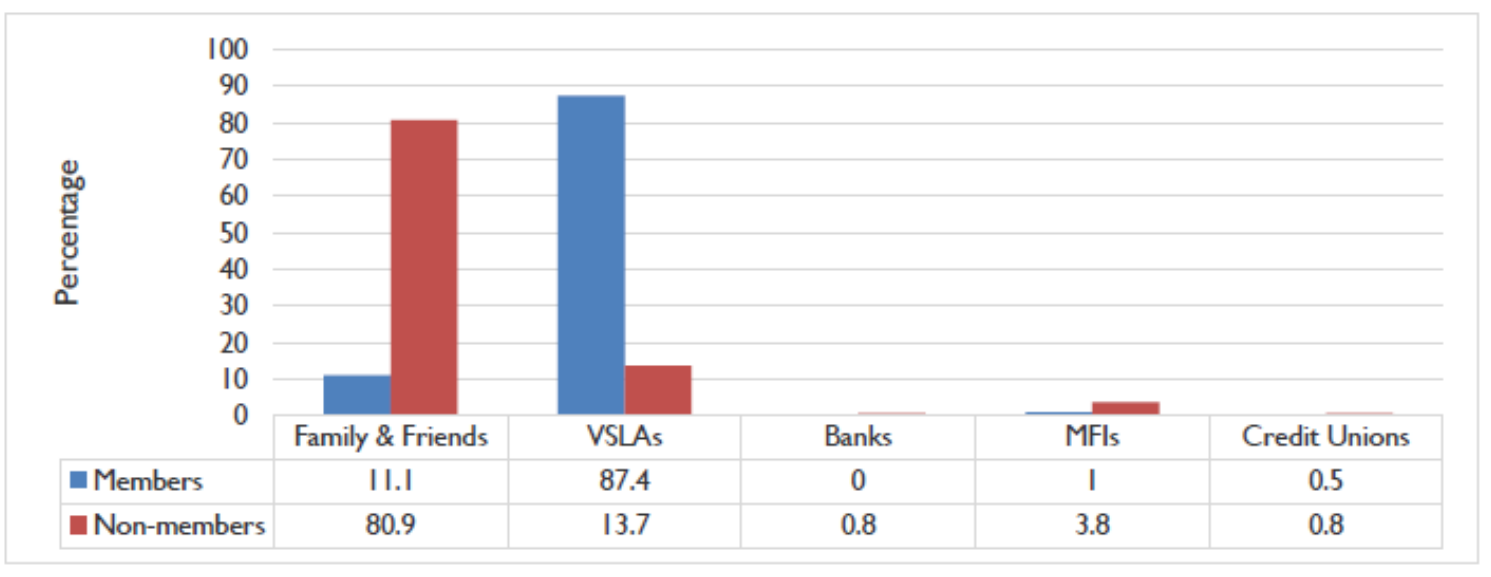

Figure 3. Comparison of credit sources between the group and non-group members

The graph shows that members of savings groups are accessing most of their credit from the group as opposed to family and friends (which also included money lenders) and banks. The in-depth interviews provide a lot of insights as to why these other sources are shunned, especially by members of the savings groups. In-depth interviews with key informants revealed that formal financial institutions such as banks are often difficult to access as accessing them involved a lot of complicated paperwork. The banks are also located very far leading to significant transportation costs, and that their interest rates are usually very high. On the other hand, even though friends and relatives are the most common source of credit, while moneylenders and traders (while considered accessible) are generally treated as a last resort as they are believed to lend at unfair terms as the following quotes show:

"... most people want to expand their businesses but cannot get loans from banks due to high-interest rates. As such, they have found a lot of benefits from the low-interest loans being offered by the savings groups..." (Community Agent, Katete).

\subsubsection{Income Generating Activities}

We assessed whether membership to savings groups is associated with increased business or entrepreneurship activities. We did this by comparing the uses of borrowed funds between members of the savings groups and non-members. Indeed, we found that respondents in the savings groups are significantly more likely to indicate that the primary reason for obtaining the loan in the past twelve months was to invest in a business. The results (Figure 4) show that among saving group members that reported borrowing money, 39.4 percent borrowed for purposes of investing in business ventures, compared to 16 percent for non-saving group members. There is also a marked difference in the proportions that reported using borrowed funds for consumption purposes such as food purchases. Comparisons show that the 
proportion of non-saving group members that indicated that the main reason they borrowed funds was to purchase food was much larger (21.4 percent) than that for saving group members (6.4 percent). These findings are similar to those reported by Karlan et al. (2012) that show that microenterprise activities are positively affected by the savings groups leading to a 6 percent increase in the number of businesses operated by households belonging to saving groups as well as a 9 percent increase in the duration of mostly short-term seasonal business activities.

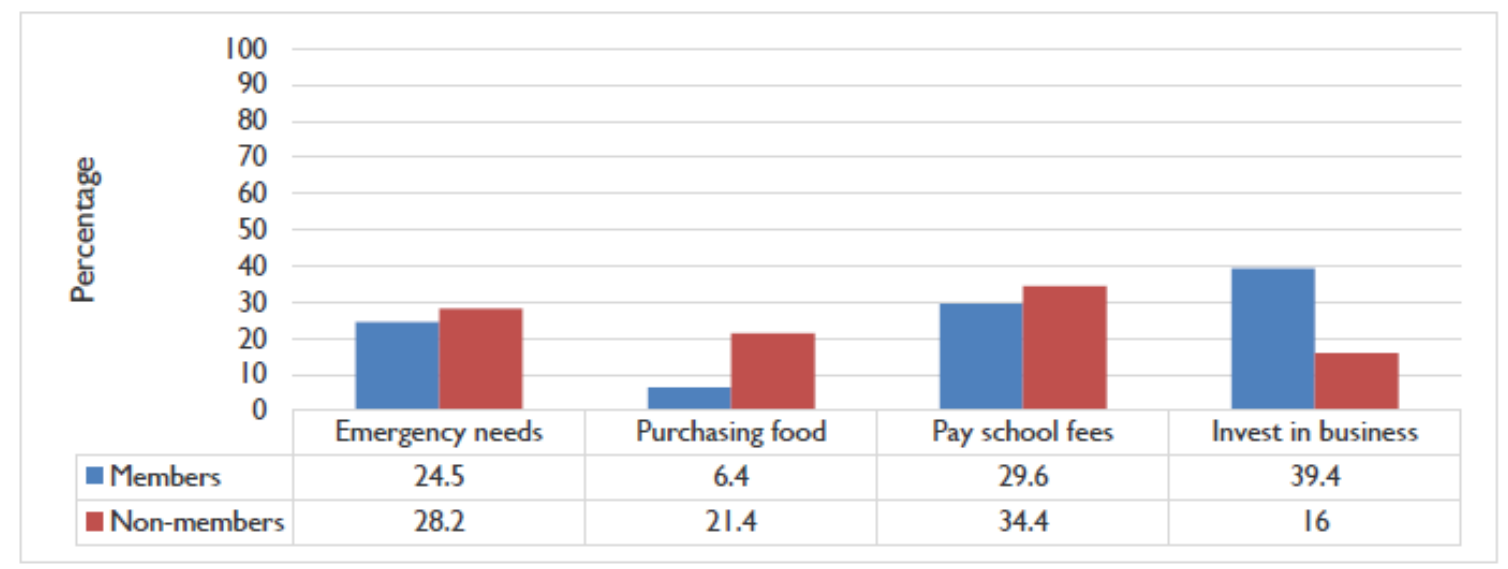

Figure 4. Reasons for borrowing money between group and non-group members

The in-depth interviews reveal that membership to savings groups has resulted in a proliferation of businesses as group members have either been borrowing to invest in businesses or using the funds after sharing out to invest in various types of businesses as well as investing into their farming activities. The following are just some of the few examples:

"...when it comes to farming we are not struggling especially when it comes to purchasing inputs such as fertilizers. Instead of waiting for the money from the e-voucher program (a government subsidy program that provides subsidized farming inputs) to reflect on our accounts before we can purchase fertilizer, we simply use the money from the share out to purchase fertilizers. This is because, for our group, we have timed the sharing out to be in November so that it coincides with the time when most farming households need money for purchasing inputs. As such, even our harvests have improved as we can apply fertilizer on time compared to those who have to wait for the subsidized fertilizers which always come late..." (Member, Katwesheko savings group, Mwamba).

\subsubsection{Reaction to Shocks}

Rural households tend to face multiple covariant and idiosyncratic shocks which often lead to downward economic mobility or increased poverty. In Zambia, some of the shocks include market access challenges caused by market liberalization policies; increased morbidity and mortality due to the HIV and AIDS pandemic and other diseases; adverse consequences of climate change and deterioration of the natural resources; adverse consequences of a family breakdown caused by spousal abandonment, divorce, and widowhood (Kalinda, 2014). Once 
faced with these shocks, households practice several coping mechanisms to address these shocks which include a range of prevention, mitigation, and coping strategies, some of which may have detrimental effects on the future welfare of the households. To assess the effects of membership to savings groups on household welfare, we asked the households how they would react to shocks they may experience.

To assess how saving group membership affects a household's ability to respond to financial shocks, the respondents were asked to provide information on how they would get money if they needed money for an emergency. The results show that saving groups member are better able to respond to covariate shocks compared to non-saving group members. We conclude so because 79.5 percent of the saving group members indicated that they would draw on their savings compared to only 6.8 percent of the non-saving group members. On the other hand, the majority (66.3 percent) of the respondents who are not members of savings groups indicated that they would have to rely on family and friends compared to 12.9 percent of savings group members. Similarly, the proportion of non-saving group members that reported that they would resort to detrimental measures such as selling assets was larger (12.4 percent) than that for savings group members (3.8 percent).

Membership to savings groups is also associated with an increased ability to respond to idiosyncratic shocks. This is because the proportion of saving group members that indicated that they would not have any means to raise money in case of an emergency was much smaller (3.8 percent) than that for non-saving group members (14.5 percent). The observation that savings group membership helps households to weather shocks without resorting to extreme measures is also collaborated by other studies. For instance, Karlan et al. (2017) show that by increasing access to credit and social funds, membership to VSLAs could enable their members to absorb the impact of these shocks using financial tools without having to sell down productive assets. Additionally, over time an increase in income and asset accumulation through profitable investments in business and agriculture is likely to improve the household's capacity to absorb shocks effectively.

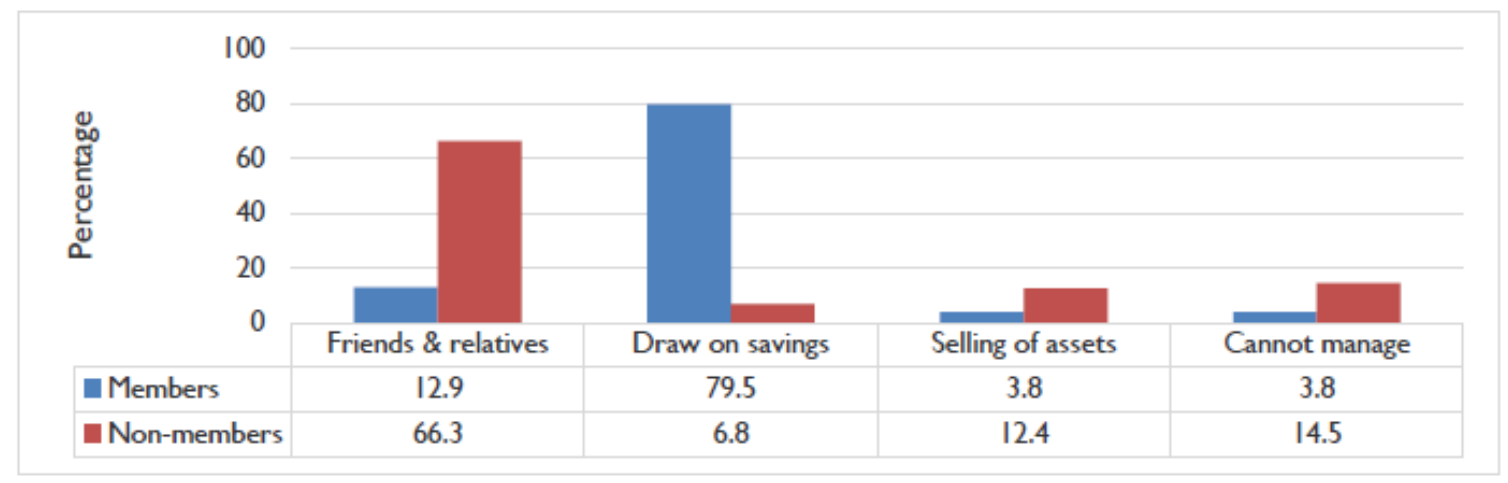

Figure 5. Methods that households can use to raise funds during emergencies

The respondents were also asked to indicate how possible it is for them to come up with a $\mathrm{K} 1,000$ within a month in an event that they were urgently required to do so. Again we found 
that the proportion of saving group members that indicated that it was very possible for them to raise a K1,000 (approximately US\$100) within a month is much higher (44.5 percent) compared to non-saving group members. On the other hand, the proportion of non-saving group members that indicated that they can't raise such an amount with a month is higher (49.4 percent) than that of saving group members (30.4 percent).

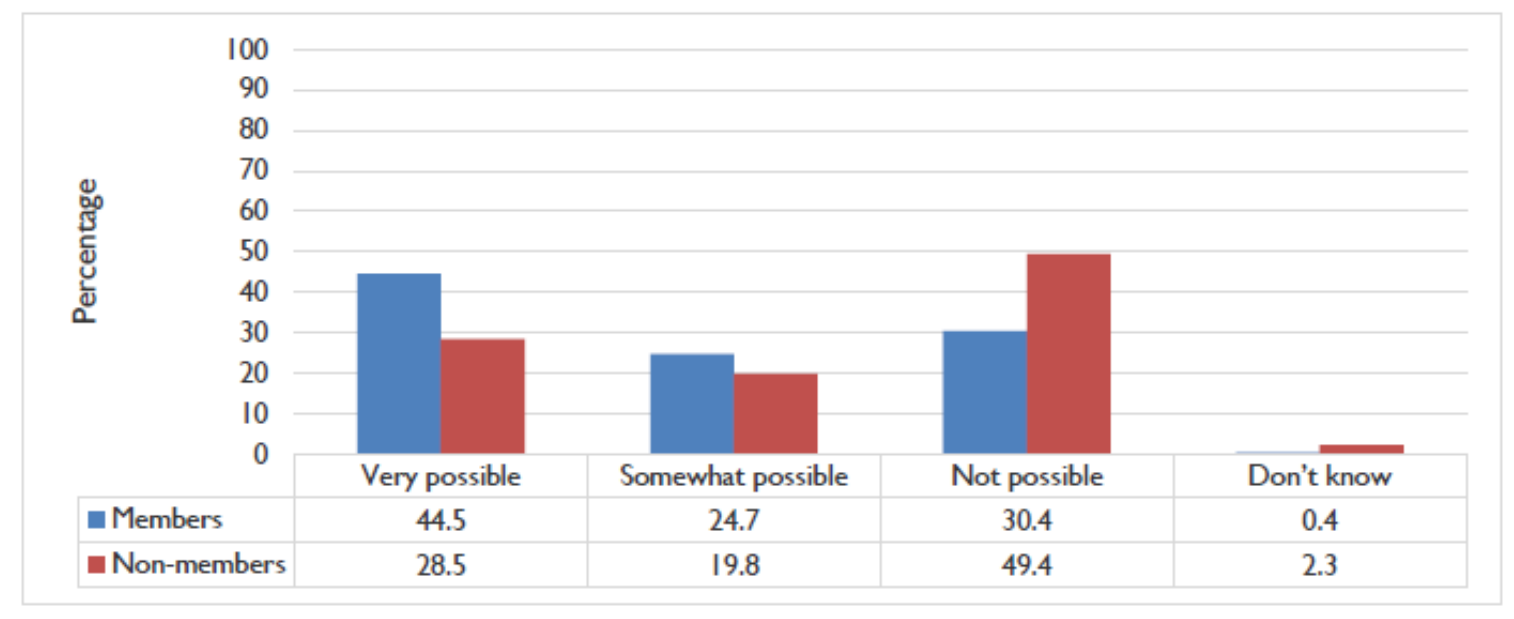

Figure 6. Possibility of raising K1,000 within a month

The fact that membership to savings groups is associated with increased household's ability to appropriately deal with shocks is also confirmed by in-depth interviews. Indeed, the majority of the respondents indicated that unlike in the past when they used to resort to money lenders, and in most cases with adverse consequences, in times of emergency, this is no longer the case with the coming of the savings groups. Others indicated that before the savings groups, it was impossible to borrow relatively large amounts of money from any source:

"...before joining the savings group, it was very difficult for me to borrow money during emergencies. This was especially true when one needed large amounts of money exceeding K1000. The people in this village are poor. No individual can lend you such a large amount of money because they simply do not have much money themselves. It is even difficult to sell livestock and raise money quickly unless you travel to the Boma which is very far. However, since joining the group, it is possible to borrow even though the amounts are still small..." (Member, Tigwilizane Savings Group, Katete).

\subsubsection{Food Security}

Because WV's integrated and tailored pathway out of extreme poverty focuses on equipping families with the knowledge, skills, and resources to ensure that among other things, children are well-nourished and free from hunger, we explore whether membership to the savings groups is associated with improved household food security. For the household food security indicator, we use dietary diversity which reflects the diversity of food consumed in the household. Knowing that households consume, for example, an average of four different food groups implies that their diets offer some diversity in both macro-and micronutrients. The 
indicator is defined as the percentage of households where food from four or more food groups was consumed in the last 24 hours. The food groups include cereals, tubers, potatoes, fruits, meat, eggs, fish, legumes, milk, and its derivatives, fats, and oils as well as sugar.

Comparison between savings groups members and non-members shows that the proportion of households belonging to savings groups that could be classified as having sufficient diet diversity was larger (76.9 percent) than that for households not belonging to savings groups (67.6 percent). This difference is statistically significant implying a significant association $(\chi 2=11.290$, d.f. $=1, p<0.05)$ between membership to savings groups and having sufficient diet diversity at the household level. However, inspection of the phi coefficient only suggests a weak though significant relationship $(\varphi=0.104, n=1,034, p<0.01)$. Examination of other literature, however, shows conflicting results with regards to the impact of savings groups on household food security. For instance, even though an evaluation of the impact of participation in savings groups on household and child nutritional outcomes in Mozambique shows that savings groups had a statistically significant and positive effect on months of food sufficiency as well as increasing household dietary diversity scores (Brunie $e t$ al., 2014), this was not the case in Ghana, Malawi, and Uganda where it was found that even though the promotion of community-based microfinance groups led to an improvement in household business outcomes and women's empowerment, even though there was no evidence of impacts on average consumption (Karlan, 2017). However, for our case these quantitative findings are also supported by the findings from the in-depth interviews with both the Community Assistants and beneficiary households who were able to show that membership to savings groups had both direct and indirect impacts on food security as the following quotes show:

"...being a member of the saving group has been very beneficial for me. Even when you come to my home, the diet has even changed. This is because I can do small businesses like selling vegetables which help me to get money to buy food. This time around I can tell you that even though I am staying in the village, I can have tea with buns whenever I want just like you who is coming from town. This is because every time I go into town to sell my vegetables, I usually buy some sugar and flour which I then use to bake buns at home for us to have tea..." (Member, Titandizane Savings Group, Katete).

Savings groups were also having an indirect impact on food security through improved agricultural production and productivity among the members. For instance, one key aspect that constantly came up was the indirect impact of membership to savings groups on improved food security through increased production. Most of the respondents were able to attest that compared to before they joined the groups, they are now able to produce more food. This is because most groups have timed the share-out period around November when input purchases are supposed to be made. As such, other than waiting for the subsidized government fertilizer, which is usually distributed late, group members simply use the money they get from the share-out to purchase their fertilizer, which when supplemented with the FISP makes them produce more crops. The following are some of the testimonies from some of the members interviewed: 


\section{Macrothink}

Business and Economic Research ISSN 2162-4860 2021, Vol. 11, No. 2

"... as a result of the savings groups, we can have food throughout the year. This is different from the way things were before where we could not produce enough food to last the whole year. Even though we have been benefiting from the subsidized fertilizer, these inputs most of the time come late. Sometimes, we could even fail to benefit from these fertilizers because for one to benefit one needs to pay membership fees to the group as well as contribute some money for transportation. In some instances, we used to fail to raise these funds. However, since I joined the group, even my yields have improved. I am now able to harvest up to four scotch carts of maize as opposed to the past when the most I could manage was two scotch carts..." (Member, Galamukani Savings Group).

\subsubsection{Impact on Asset Accumulation and Poverty}

The accumulation of durable assets is one of the specific pathways that households can use to generate long-term sustainable improvements in household wellbeing. Indeed, Sebstad and Cohen (2001) identify three main pathways through which microfinance services can reduce vulnerability namely income smoothing, building assets (including financial, physical, human, and social assets), and empowering women. Following Karlan et al. (2012), we test for impacts of the VSLA program on asset accumulation and home improvements. This could happen through one of three mechanisms: (1) the increased ability to accumulate savings then makes lump-sum investments more feasible, particularly through end-of-cycle savings share-outs, (2) the social fund and loans from the group substitute sales of assets as a means to react to shocks and afford other necessary expenses, and (3) the growth of enterprise or farm outputs if the VSLA leads to increased and profitable investments.

The respondents were asked to provide information on whether they owned assets such as televisions, pressing irons, mobile phones, and beds with mattresses to assess the impact of membership into saving programs on household asset accumulation. Comparison between savings group members and non-members shows that the proportion of savings group members that owned televisions was higher (26.0 percent) than that for non-members $(10.9$ percent). This difference is statistically significant $\left(\chi^{2}=39.329\right.$, d.f. $\left.=2, p<0.05\right)$. Furthermore, inspection of the phi coefficient suggests a moderate but significant relationship $(\varphi=0.195, n=1,034, p<0.01)$ between group membership and TV ownership. Significant differences are also observed with regards to ownership of pressing irons $\left(\chi^{2}=43.248, d . f .=\right.$ $2, p<0.05)$; mobile phones $(\chi 2=12.851, d . f .=1, p<0.05)$ and beds with mattresses $\left(\chi^{2}\right.$ $=87.101$, d.f. $=2, p<0.05)$ implying that membership to savings groups is associated with increased ownership of selected durable assets (Figure 7). 


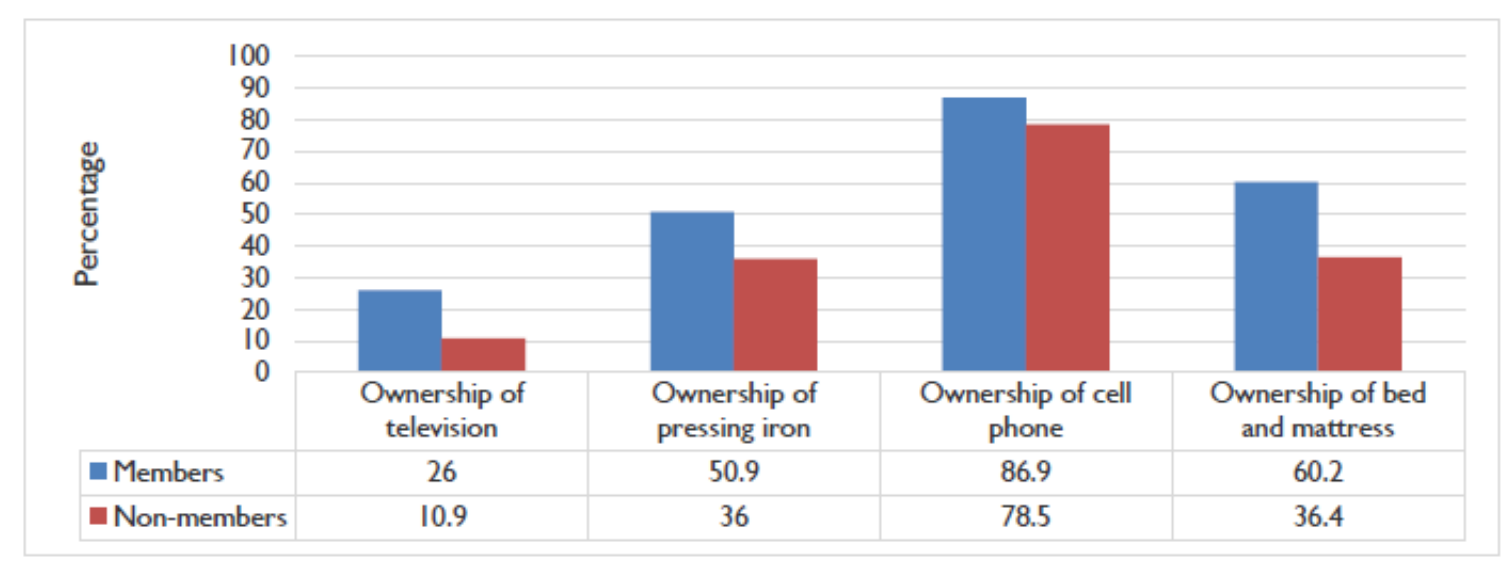

Figure 7. Ownership of selected household assets by group membership

The observation that membership to savings groups is associated with increased ownership of selected assets is supported by data from qualitative interviews. A good number of the respondents interviewed indicated that they are much able now to purchase even those household goods that they could not afford before joining the group:

"...for me, the biggest thing I have achieved since joining the group is that I have managed to build an elevated house for the goats. After we shared out, I was able to buy 14 iron sheets. Initially, I only had a small goat house but with the extra money from the loan, I was able to extend it. I was also able to install a solar system as well as purchase a television and a home theatre system..." (Group Member, Chikumbuso Savings Group, Katete).

"...even in our homes, things have changed. There are those household goods that we never used to have in the past which we are now able to afford due to membership in these savings groups. This is because by saving small amounts of money, the money accumulates and once you get it, it's a lot of money and one can get bigger assets that one could not afford before. Either you buy a mattress if you did not have one or you buy a mattress for the kids if they did not have any. As opposed to the way things used to be in the past when we just used to put empty grain bags on the floor for children to sleep on, this is no longer the case for most members in the groups as they can buy mattresses even for children..." (Community Agent, Mwamba).

"...we have also bought a lot of household stuff which makes life easy. For instance, in the past, we used to go and soak cassava by the river in the dambos. However, most women realized that it was quite cumbersome to walk for miles to the river just to soak cassava in dambos. However, this is no longer the case for most women as using loans from the savings groups, we have been able to purchase that we are using to soak cassava in the comfort of our homes..." (Member, Twafwane Savings Group, Mwamba).

We also investigate the impact of membership to savings groups on respondents' housing characteristics. For this, we use the quality indicators of floors, roofs, as well as cooking energy mainly used. Comparison between savings group members and non-members shows 
that the proportion of savings group members whose homes had concrete floors was higher (40.7 percent) than that for non-members (21.5 percent). This difference is statistically significant $(\chi 2=43.999$, d.f. $=2, p<0.05)$. Furthermore, an inspection of the phi coefficient suggests a moderate but significant relationship $(\varphi=0.206, n=1,034, p<0.01)$ between group membership and quality of the housing floors. Similarly, we find significant differences in proportions of households with iron roofs $\left(\chi^{2}=57.600\right.$, d.f. $\left.=1, p<0.05\right)$. Again, an inspection of the phi coefficient suggests a moderate but significant relationship $(\varphi$ $=0.236, n=1,034, p<0.01)$ between group membership and quality of the housing roofs. However, even though we also find significant differences in proportions of households using improved energy for cooking $\left(\chi^{2}=20.737\right.$, d.f. $\left.=2, p<0.05\right)$, an inspection of the phi coefficient suggests a weak but significant relationship ( $\varphi=0.142, n=1,034, p<0.01$ ) between group membership and quality of energy mainly used for cooking (Figure 8).

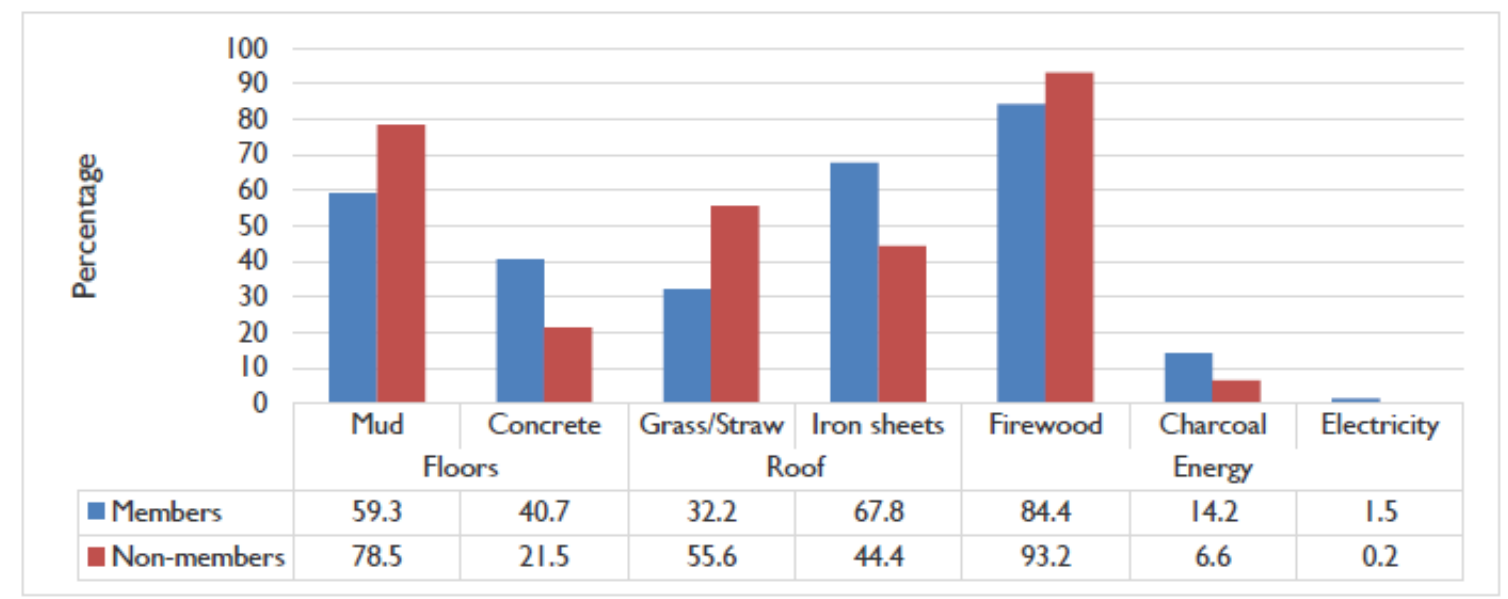

Figure 8. Housing characteristics and group membership

These quantitative findings are collaborated by the findings from in-depth interviews. A large proportion of the respondents interviewed revealed that even the quality of life in their homes has changed as a result of membership to savings groups. According to these respondents, unlike in the past when they used to stay in grass-thatched houses, they are now able to afford iron sheets and cement for concrete on their floors. The following quotes and photos show some of the examples.

"...mainly when one looks back, things have changed. We mostly used to stay in grass-thatched houses and also depended a lot on our husbands even for small things like salt. However, since joining the savings groups, things have changed and we are also now contributing to the running of our homes financially..." (Member, Katwesheko Savings Group, Mwamba).

"...even with regards to homes, a lot of people in the savings groups are now able to stay in homes that are roofed with iron sheets... a lot of women have bought iron sheets for their homes. Even though the houses are small, most can afford even 20 pieces of iron 
sheets and put them on the roof. This is much better than sleeping in a grass house..." (Community Agent, Mwamba).

Finally, we use the Progress out of Poverty Index (PPI) to assess whether membership to savings groups is associated with poverty levels. The PPI is a rapid assessment tool designed to estimate the poverty level of potential microfinance clients using a set of 10 indicators. The set of indicators predicts the probability that a given household is living under a particular poverty line, based on the most recent national household survey. According to the PPI index, 84.9 percent of the total sample is living under the $\$ 1.25$ poverty line. Disaggregation by membership to savings groups shows that the poverty rate (proportion of households that lived under $\$ 1.25$ a day) among saving group members is lower (81.6 percent) than that for non-saving group members (88.8 percent). This difference is statistically significant $(\mathrm{t}=$ 5.498; $\mathrm{p}<0.05)$.

\section{Conclusion}

The findings tend to support the hypothesis that membership to savings groups can lead to changes in the financial tools that respondents use to manage expenditures and investments. We base this conclusion on the finding that savings group members are less likely to borrow from family and friends as well as money lenders, both of which are sources of credit that are associated with other negative effects on the borrowers. The findings also support the hypothesis that these short-term changes in behavior, and the prolonged usage of a wider set of financial tools, lead to the creation of wealth and ultimately, changes in the well-being of households in the long run. This is supported by both the qualitative and quantitative findings which show significant differences in nutrition, ability to send children to school, asset accumulation, and the probability of being poor among saving group members and non-members. Furthermore, these findings also highlight the key role that saving groups play in poverty reduction through equipping households with resources for ensuring that children are well-nourished, families have adequate and resilient incomes and assets, and that families have resources to be in school as theorized in the World Vision's integrated and tailored pathway out of extreme poverty.

However, it is also important to note that the validity of these findings is likely to be influenced by selectivity bias, considering that membership to these groups is not a random process. Indeed, a comparison between the two groups in terms of the demographic characteristics shows that they are significantly different on three out of the four characteristics that were compared. This implies that some of the observed differences in the welfare indicators cannot be attributed to membership to the savings groups as they could be resulting from demographic differences. This limitation implies that there is an opportunity for further research on this subject. Specifically, there is a need to do a randomized trial, with the participants and non-participants being assigned to groups randomly to eliminate bias.

\section{Acknowledgment}

The authors wish to appreciate and acknowledge the efforts of various stakeholders without whom this study not have been possible. First of all, the World Vision (Zambia) Sustainable 


\section{Ml Macrothink}

Business and Economic Research ISSN 2162-4860 2021, Vol. 11, No. 2

Enterprise and Economic Development (SEED) team are being acknowledged for having provided the funding for this research as well as technical support. The communities in the three APs that took time off their busy schedules to answer to the interviews are also acknowledged. Finally, we wish to acknowledge the tireless efforts of the data collectors who, sometimes worked late, to ensure that we had this high-quality data.

\section{References}

Allen, H., \& Panetta, D. (2010). Savings groups: What are they. Washington DC: SEEP Network, 2.

Ritchie, A. (2010). Community-based financial organizations (No. 18 (3)). International Food Policy Research Institute (IFPRI).

Ashraf, N., Karlan, D., \& Yin, W. (2006). Tying Odysseus to the mast: Evidence from a commitment savings product in the Philippines. The Quarterly Journal of Economics, 121(2), 635-672. https://doi.org/10.1162/qjec.2006.121.2.635

Brunie, A., Fumagalli, L., Martin, T., Field, S., \& Rutherford, D. (2014). Can village savings and loan groups be a potential tool in the malnutrition fight? Mixed method findings from Mozambique. Children and Youth Services Review, 47, 113-120.

https://doi.org/10.1016/j.childyouth.2014.07.010

Carroll, T., Stern, A., Zook, D., Funes, R., Rastegar, A., \& Lien, Y. (2012). Catalyzing Smallholder Agricultural Finance (Sept. 2012). Dalberg Global Development Advisors. [Online] Available: http://dalberg.com/documents/Catalyzing Smallholder_Ag_Finance.pdf

International Finance Corporation (2011). Scaling Up Access to Finance for Agricultural SMEs: Policy Review and Recommendations. Global Partnership for Financial Inclusion. [Online] Available: http://www.gpfi.org/sites/default/files/documents/G20_Agrifinance_Repo $\mathrm{rt} \% 20$ (FINAL\%20ONLINE).

International Finance Corporation. (2014). Access to Finance for Smallholder Farmers: Learning from the Experiences of Microfinance Institutions in Latin. Global Partnership for Financial Inclusion.

Kalinda, T. (2014). Multiple shocks and risk management strategies among rural households in Zambia's Mazabuka District. Journal of Sustainable Development, 7(5), 52-67. https://doi.org/10.5539/jsd.v7n5p52

Karlan, D., Thuysbaert, B., Udry, C., Cupito, E., Naimpally, E., Salgado, E., \& Savonitto, B. (2012). Impact assessment of savings groups: Findings from randomized evaluations of CARE village savings and loans associations in Ghana, Malawi, and Uganda. Final Report. Innovations for Poverty Action (IPA). New Haven, USA.

Karlan, D., Savonitto, B., Thuysbaert, B., \& Udry, C. (2017). Impact of savings groups on the lives of the poor. Proceedings of the National Academy of Sciences, 114(12), 3079-3084. https://doi.org/10.1073/pnas.1611520114 


\section{Macrothink}

Business and Economic Research ISSN 2162-4860 2021, Vol. 11, No. 2

Ledgerwood, J., \& White, V. (2006). Transforming microfinance institutions: providing full financial services to the poor. The World Bank. https://doi.org/10.1596/978-0-8213-6615-8

Ministry of Finance [MoF] (2017). National Financial Inclusion Strategy for Zambia (20172022). Lusaka, Zambia

Rasmussen, O. D. (2011). Methods for Assessing community-managed Microfinance in Malawi: Using a Randomized Control Trial to Overcome Non-Random Programme Placement. University of Southern Press, Copenhagen.

Van Rooyen, C., Stewart, R., \& De Wet, T. (2012). The impact of microfinance in sub-Saharan Africa: a systematic review of the evidence. World Development, 40(11), 2249-2262. https://doi.org/10.1016/j.worlddev.2012.03.012

Sebstad, J., \& Cohen, M. (2001). Microfinance, risk management, and poverty: Synthesis study. Consultative Group to Assist the Poorest (CGAP), World Bank.

World Vision Zambia Limited. (2017). Sustainable Enterprise and Economic Development (SEED) Technical Programme document.

Yin, R. K. (1994). Case Study Research: Design and Methods (3rd ed.). Sage publications Newbury Park, CA.

\section{Copyright Disclaimer}

Copyright for this article is retained by the author(s), with first publication rights granted to the journal.

This is an open-access article distributed under the terms and conditions of the Creative Commons Attribution license (http://creativecommons.org/licenses/by/4.0/). 